Luca Baccelli. Enseña Filosofía del Derecho en la Scuola di Giurisprudenza de la Università di Camerino, anteriormente profesor en la Università di Pisa y en la Università di Firenze. Es Visiting Scholar de la University of East Anglia (Norwich, R.U.), de la New School y de la Columbia University (Nueva York, EE.UU.). Es presidente de Jura Gentium. Centre of Philosophy of International Law and Global Politics. Forma parte del comité científico de Iride. Filosofia e discussione pubblica. Autor de Praxis e poiesis nella filosofia politica moderna, Franco Angeli, Milano, 1991; Il particolarismo dei diritti, Carocci, Roma, 1999; Critica del repubblicanesimo, Laterza, Roma-Bari, 2003; I diritti dei popoli, Laterza, Roma-Bari, 2009.

Contacto: luca.baccelli@gmail.com 


\title{
LOS DERECHOS ENTRE \\ HARD POWERS Y SOFT LAW
}

\author{
Luca Baccelli
}

Università di Camerino

\section{HUMAN RIGHTS BETWEEN HARD POWERS AND SOFT LAW}

DOI: $10.17450 / 150203$

Fecha de recepción 25 de setiembre 2015; fecha de aceptación 20 de octubre 2015. El artículo es fruto de un proyecto de investigación desarrollado en la Scuola di Giurisprudenza de la Università di Camerino y en la Columbia University.

\section{Resumen}

La globalización ha llevado a una fragmentación de las fuentes del derecho y la primacía del derecho legislativo sucumbe ante la forma-contrato y la jurisdicción. De ahí que en eso algunos autores adviertan la recuperación de la verdadera "esencia" del derecho o capten las señales de un rule of law global y de un constitucionalismo internacional. Sin embargo, en el espacio global también los derechos humanos han perdido su carácter prescriptivo y corren peligro de legitimar poderes avasallantes y desigualdades profundas. $\mathrm{Si}$, en la modernidad, los derechos brotaron de los procesos sociales de reivindicación, hoy día también los conflictos aparecen fragmentados, mientras que la gobernanza global neutraliza la lucha política. Incluso se podrían imaginar procesos por medio de los cuales el derecho puede recuperar su papel para la formación tanto de los grupos sociales como para la definición del ámbito de los conflictos sociales. 


\section{Palabras clave}

Globalización, derecho global, conflictos sociales, derechos, reivindicación.

\section{Abstract}

Globalization produced a fragmentation of sources of law, and the primacy of statute law has been replaced by contract law and jurisdiction. Some authors hail the resurgence of the very "essence" of law or catch sights of a global rule of law and an international constitutionalism. But in the global space even human rights have lost their prescriptive character and risk to legitimize overwhelming powers and deep inequalities. If in modern times new rights arises from social processes of claiming, today conflicts too appear to be fragmented, whereas global governance neutralizes political struggles. But it would be possible to re-imagine ways in which law regains its role in framing and organizing social groups such as in shaping the fields of social conflicts.

\section{Keywords}

Globalization, global law, social conflicts, rights, claiming.

\section{Fragmentaciones e invasiones: ¿el lado oscuro de la templanza?}

Llevamos sabiendo desde hace más de una década que la globalización ha producido profundas transformaciones en el derecho y en las relaciones entre los sistemas jurídicos, políticos, económicos y sociales. El desplazamiento de equilibrios y poderes de los Estados a los mercados, de la política a la economía y a las finanzas, de los gobiernos nacionales a la gobernanza transnacional anda junto con una crisis de la forma jurídica que se había afirmado en el siglo XX. En realidad, ya en los años setenta el funcionalismo sistémico destacó la reducción de la capacidad reglamentadora e integrativa del sistema jurídico en las sociedades complejas. Renunciando a la idea de derecho como expresión de la voluntad del soberano o de una ley natural "objetiva", numerosas teorías contemporáneas del derecho -partiendo de las hermenéuticas, pasando por las neoinstitucionalistas hasta llegar al neoconstitucionalismo- parecen admitir la existencia de conflictos entre normas diferentes, principios, sistemas jurídicos. Por un lado, se afirma el criterio de la sensatez para equilibrar los principios contrastantes, por otro lado, se 
admite la posibilidad de que el derecho, más que realizar la paz social, favorezca la conflictualidad. Las estructuras enrevesadas de los sistemas jurídicos habían sido analizadas por las nuevas versiones del pluralismo jurídico en términos de "interlegalidad" (interlegality): "We live in a time of porous legality or of legal porosity, of multiple networks of legal orders forcing us to constant transitions and trespassings"'.

La globalización ensancha aún más los confines de los ordenamientos que influyen el uno en el otro hasta formar "híbridos jurídicos"2. Los Estados ya no poseen el monopolio de la producción del derecho, ni tampoco las instituciones públicas supranacionales: entran en juego sujetos privados o semipúblicos (corporaciones transnacionales, sociedades de revisión contable y de certificación, burocracias internacionales del FMI, del Banco Mundial, de la Comisión Europea, ONG); y una parte de las exigencias normativas se satisfacen comprando à la carte el derecho hacia las transnational law firms y los tribunales arbitrales o por medio del forum shopping y el empleo de la competencia entre diferentes jurisdicciones. Dentro de las eventuales "posibilidades" sobresalen el riesgo y la incertidumbre y triunfan más "principios operativos y filosofías organizativas de tipo general"'3 que normas prescriptivas, y la previsibilidad del derecho disminuye.

Sabemos que se ha traído a colación una nueva lex mercatoria, aludiendo a la expansión del ámbito de las reglamentaciones privadas que prescinden del derecho de los Estados nacionales y que prefiguraría una gubernamentalidad autónoma de los mercados. La primacía de la ley parece haber sido sustituida por una hegemonía de la forma-contrato que, además del derecho privado, también se emplea en el derecho constitucional, en el derecho administrativo y en el penal. Junto con el derecho jurisdiccional, produce normas menos rigurosas que las del derecho legislativo, y parece ser más adecuada para la conciliación y el equilibrio de los intereses. Just in time: contratos y jurisdicción producen normas en el corto plazo que se pueden corregir si es necesario, poseen escasos rasgos políticos y facilitan una combinación variable entre lo público y lo privado. Reaparecen modalidades jurídicas basadas en lo fáctico, en la costumbre, en el derecho no escrito, mientras que la difusión del soft law desalienta las caracterizaciones del derecho, convirtiéndolas en normatividad sancionada. Las normas pierden su carácter dogmático, “dependiendo de la acción de individuos y grupos que compiten entre sí y que son

\footnotetext{
1. B. de Sousa Santos, "Law, A Map of Misreadings, Towards a Postmodern Conception of Law", en Journal of Law and Society, 14, 1997, pp. 29-98.

2. B. de Sousa Santos, Derecho y emancipación, Cedec, Quito, 2012, p. 116.

3. M. R. Ferrarese, Le istituzioni della globalizzazione, Diritto e diritti nella società transnazionale, il Mulino, Bologna, 2000, p. 70 .
} 
empujados por finalidades e intereses específicos"4 y al derecho "a menudo le cuesta distinguirse de lo que no es derecho"s.

La atenuación de la imagen weberiana del derecho como ordenamiento coercitivo, garantizado por el monopolio de la fuerza física ejercido por el Estado en un determinado territorio, y que deriva su legitimidad de su "calculabilidad" racional, se cruza con la desaparición de la diferenciación funcional del subsistema jurídico, ya analizada por Niklas Luhmann. Particularismo, pluralismo, producción jurisprudencial del derecho, estratificación de las fuentes, primacía de la ordinamentalidad respecto de la normatividad: como es notorio, muchos han captado numerosas analogías entre el derecho global y el orden jurídico medieval. Paolo Grossi percibe esta fragmentación y privatización de las fuentes como una auto-organización de los particulares que, frente a la flema y a los incumplimientos de lo público, recurren a expertos para inventar "instrumentos útiles que pongan en orden sus negocios jurídicos". Las reglas dúctiles elaboradas por "una ciencia sensible" derivan "de un movimiento espontáneo de aquella realidad variada y móvil que es el mercado" . Así que la globalización jurídica nace desde abajo, incluso recuerda el "espíritu del pueblo" de Savigny. Con respecto a eso, Grossi vislumbra un regreso a la función originaria y a la "esencia misma del derecho" que se había perdido "en el triunfo de lo 'público', de lo 'absolutamente público' sobre lo 'privado', en el monopolio por parte de lo 'político' de toda dimensión de la vida social”'. En este panorama, el jurista "sabe que ha recobrado un papel central en la sociedad".

Sin embargo, los críticos han destacado que la globalización conlleva poderes oprimentes y aumenta las desigualdades de forma rebosante. Ya en 1997, el 20\% más rico de la población poseía el $86 \%$ del PIB mundial, dejándole al $20 \%$ más pobre solo el $1 \%{ }^{10}$. Los que defendían la globalización afirmaban que si a los mercados se les dejaba actuar libremente corregirían estas deformaciones y mejorarían la condición de los más pobres. Hoy día la imponente obra de Thomas Piketty niega esta tesis y, recientemente, un informe de Oxfam ha mostrado que, en 2014, los patrimonios del 1\% de los más ricos alcanzan el 48\% de la totalidad y, en 2016, los superarán del restante

\footnotetext{
4. M. R. Ferrarese, "Governance: a Soft Revolution with Hard Political and Legal Effects", en Soft Power, 1, 2014 , p. 54.

5. G. Zaccaria, La comprensione del diritto, Laterza, Roma-Bari, 2012, p. 50.

6. P. Grossi, Prima lezione di diritto, Laterza, Roma-Bari, 2003, p. 69.

7. Ibid., p. 75.

8. Ibid., p. 30.

9. Ibid., p. 112.

10. En 1960, el quinto país más rico poseía el 70,2\% y el más pobre el 2,3\%: esta relación pasó de 30:1 a 86:1 (cfr. L. Gallino, Globalizzazione e disuguaglianze, Laterza, Roma-Bari, 2000, p. 71); entre 1980 y 2007, en los 15 países más ricos del OSCE, el factor de las rentas de trabajo en el PIB disminuyó del 68\% al 58\%, en provecho de rentas y beneficios (cfr. Id., La lotta di classe dopo la lotta di classe, Laterza, Roma-Bari, 2012, pp. 104-105).
} 
99\%. Bajo otra perspectiva y a pesar de las numerosas conferencias sobre el tema, los retrasos y las incapacidades de adoptar políticas eficaces contra el calentamiento global son el indicio más evidente de la escasa utilidad de la gobernanza global a la hora de gestionar de forma equilibrada las relaciones entre la humanidad y su medio ambiente natural.

Por otra parte, tampoco se puede decir que las transformaciones contemporáneas del derecho son espontáneas y que proceden de abajo. La liberalización asimétrica del comercio internacional, las políticas de "saneamiento" intimadas por las instituciones internacionales con las consiguientes "reformas" que desvalorizan las políticas sociales y neutralizan los derechos sociales, el dominio mismo de las finanzas sobre la economía real y la política, todo esto brotó de una serie de decisiones políticas, inspiradas por una ideología fuerte. Además, siguen siendo los Estados los que, en última instancia, posibilitan las transacciones comerciales, continúan las políticas proteccionistas y actúan en las instituciones transnacionales ${ }^{11}$.

En su último libro, Alfonso Catania subrayaba que, en el derecho global, los actores poseen garantías deshomogéneas y muy precarias. Ante los conflictos, "la representación irénica de la autorreglamentación [...] desaparece detrás de una negociación frágil y contingente en la que el derecho se limita a ofrecer su técnica para redactar los acuerdos, pero no logra [...] ser eficaz" ${ }^{\prime 2}$. El pluralismo de los ordenamientos, la dudosa estratificación de las fuentes, los atravesamientos soft, la afirmación de la lógica estratégica, el debilitamiento de la prescriptividad parecen convertirse en una casi completa funcionalización del derecho a los procesos en marcha, en la incapacidad de oponer principios inderogables y normas sancionadas a praxis económicas y elecciones políticas que ponen en tela de juicio el patrimonio constitucional adquirido durante el siglo XX, hasta cuando "se consoliden ámbitos de poder neo-absolutistas"13. Aquí se insertan el "muy fuerte y casi feroz conflicto de las interpretaciones"14 por el cual se interesó Giuseppe Zaccaria, y la dificultad de detectar un ámbito común para el pluralismo y la "dispersión de las fuentes", de lo cual habló Francesco Viola. Parece que el Law as Disagreement está relacionado con la gubernamentalidad neoliberal, y no es impotente frente a ella; "el derecho jurisprudencial y el derecho contractual son fundamentales hoy día por su capacidad de adaptarse doblemente a la actual tendencia a la privatización"15.

11. M. Hardt, A. Negri, Multitude, Harvard University Press, Cambridge (Mass.) 2004, pp. 167-176.

12. A. Catania, Metamorfosi del diritto. Decisione e norma nell'età globale, Laterza, Roma-Bari, 2008, pp. 68-69.

13. G. Zaccaria, La comprensione del diritto, p. 52.

14. Ibid., p. XII.

15. M. R. Ferrarese, “Governance”, p. 54. 
Recordando el título de la obra fundamental de Gustavo Zagrebelsky, la apacibilidad tiene un lado oscuro ${ }^{16}$.

\section{Rule of law: ¿una marca global?}

Sin embargo, algunos autores niegan la tesis por la que las metamorfosis han llevado a una especie de caótica anarquía. Maria Rosaria Ferrarese subraya que la misma lex mercatoria sufre procesos de institucionalización. Sabino Cassese sostiene que los principios típicos del Estado de derecho se afirman a pesar de haber muchas graduaciones sectoriales, de emerger formas transnacionales de gobierno y de estar desarrollándose un poder judicial global ${ }^{17}$, hasta el nacimiento de un International constitutionalism ${ }^{18}$. Rule of law se convierte en "una marca internacional que se puede emplear a nivel global para tutelar los derechos e incluso el mercado" ${ }^{19}$. Bajo esta perspectiva, se destacan sobre todo los derechos humanos que, por un lado, contribuyen a legitimar el derecho global y, por otro lado, impiden su deshumanización. A pesar de la pretensión universalista, emergen conflictos entre concepciones diferentes, principios antinómicos, diferentes lenguajes de los derechos que se entrelazan en el espacio global. Y se pone en tela de juicio el mismo carácter jurídico de los derechos: estos adquieren "cada vez matices éticas, culturales, políticas y sociales”.

Siendo un "tema jurídico de escasa tecnicidad" y estando ambiguamente relacionados con la legalidad, es fácil considerar los derechos "desde abajo"20, aunque estén obligados a una existencia incierta, a un contenido variable. Los documentos supranacionales sobre los derechos humanos pierden su valor, convirtiéndose en "formas de comunicación, a medias entre la enunciación de principios éticos y el proyecto jurídico" ${ }^{21}$. La definición y la protección de los derechos se deben a "una 'lucha' que hay que llevar en lo cotidiano, además que en los tribunales"22. Los tribunales y su "diálogo de constitucionalismo" juegan el papel decisivo de garantizar los derechos; también la justicia llega a ser glocal, y los derechos “se relacionan con el 'aquí y ahora', que en otro

16. Cfr. G. Zagrebelsky, Il diritto mite, Einaudi, Torino, 1992.

17. S. Cassese, Oltre lo Stato, Laterza, Roma-Bari, 2006, p. 21, pp. 109-179.

18. Ibid., 26-29, 189.

19. M. R. Ferrarese, “Governance”, p. 51.

20. M. R. Ferrarese, Il diritto al presente, Globalizzazione e tempo delle istituzioni, il Mulino, Bologna, 2002, p. 164.

21. Ibid., p. 169.

22. Ibid., p. 145. 
lugar pueden no funcionar o sufrir reajustes"23. Así las cosas, parece que los derechos se limitan a testimoniar una relación -ambivalente- con algunos principios generales y algunos valores, sin poner en tela de juicio las dinámicas de la gubernamentalidad neoliberal ${ }^{24}$; como mucho representan su interfaz aceptable.

De ahí que otros autores consideren la globalización jurídica como la parte contraria de la concentración y confusión de los poderes económicos y políticos, de un mercado falseado para el provecho de los países más ricos, de la explotación ilimitada del trabajo, de la destrucción del medio ambiente natural. Pues bien, los derechos parecen contener todos los límites y las ambivalencias del soft law respecto de los hard powers, acabando por ser funcionales a estos. Para Luigi Ferrajoli, la alternativa sería otorgarles a agencias internacionales reformadas la función de garantizar los derechos fundamentales; esto debería facilitar "la restauración" (el término es significativo) "del papel de gobierno de la esfera pública y de su separación de la esfera privada" ${ }^{25}$, imponiendo sistemas de incompatibilidad rígidos y vínculos legales a la lex mercatoria. Además, las instituciones supranacionales de garantía deberían empezar a proteger el trabajo internacionalmente y limitar la autonomía empresarial; lo cual permitiría disminuir la pobreza y tutelar los bienes sociales fundamentales. Delineando esta especie de "justicia global a través del derecho", a su vez Ferrajoli subraya el papel y la responsabilidad de los juristas ${ }^{26}$, aunque no se interrogue acerca de quien debería ocuparse de ella y desatiende el tema de la coerción: esto es, no se interesa por la posibilidad que las agencias internacionales reformadas tendrían si promocionaran realmente los derechos, si sancionaran sus violaciones, frente a la apremiante fuerza militar de los Estados, de las organizaciones criminales, de las redes del terrorismo, y al exceso de poder -no solo económico- de las corporaciones transnacionales.

Pero no solo se trata de realizarlo prácticamente. Para Ferrajoli, el globalismo jurídico atañe a una visión formalística del derecho y de la interpretación, a una metaética que implica la autocerteza de los principia iuris o, por lo menos, una negociación sin ambivalencias y antonomías, que se pueden evitar gracias al "empleo constante de los conceptos [...] con el único y unívoco significado con el que fueron definidos"27. Si por lo menos un siglo de epistemología y metaética pusieron radicalmente en tela de juicio

\footnotetext{
23. Ibid., p. 185.

24. Cfr. L. Bazzicalupo, "Diritti e valutazione nella governamentalità neoliberale”, en Ars Interpretandi, 1, 2015.

25. L. Ferrajoli, Principia iuris, Teoria del diritto e della democrazia, Laterza, Roma-Bari, 2007, II, p. 583.

26. "Hay una paradoja epistemológica que caracteriza a nuestras disciplinas: el universo que describen lo construyen ellas, por lo menos por una parte" (ibid., p. 608).

27. Ibid., I, 57. Nótese que en el modelo de Principia iuris los principios no se pueden reinterpretar: no solo no hay ningún círculo hermenéutico, sino tampoco el método rawlsiano del equilibrio reflexivo.
} 
estas expectativas, otras versiones del globalismo jurídico que garantizan su inalienabilidad acogen el universalismo del fundamento de los derechos humanos. Los riesgos relacionados con este planteamiento ya se destacaron en un debate emprendido en el siglo XVI por Las Casas y Montaigne, que luego fue promovido por la antropología cultural y hoy concierne a estudios de género, a las teorías poscoloniales y, claro está, a la filosofía política y jurídica ${ }^{28}$.

Estamos frente a una alternativa desalentadora. Por un lado, si se reconoce que las motamorfosis del derecho global enfatizan el carácter contextual de los derechos y de los principios constitucionales parece que tenemos que rendirnos frente a su débil prescriptividad, pues, a la impotencia frente a los poderes globales y locales, si no queremos aceptar que actúan para la legitimación ideológica de los ámbitos de opresión y desigualdad. En cambio, si para reivindicar su inderogabilidad se subraya su absolutidad y la universalidad de sus cimientos, entonces se corre el riesgo de que ellos acaben "funcionando como un localismo globalizado, una forma de globalización desde el alto" ${ }^{29}$. En efecto, considerados como "right and true for every person, in every society", derechos humanos y principios liberal-demócratas se emplearon mucho en el pasado reciente como argumento ideológico en apoyo a operaciones imperiales de exportación de la democracia y de guerras "humanitarias". Paradójicamente, ambas visiones parecen favorecer igualmente a las estructuras de poder existentes.

Tal vez sea posible una hipótesis alternativa. Sabemos que ya Rudolf von Ihering consideraba la historia del derecho como "la imagen de la búsqueda, del combate, de la lucha”, y la reivindicación como una contribución a la evolución del sistema jurídico para todos los asociados ${ }^{30}$. A lo largo del siglo XX, por el conflicto como factor de innovación normativa se interesaron los clásicos de la sociología y de la teoría jurídica, empezando por Max Weber, pasando por Roscoe Pound y llegando a Lewis Coser ${ }^{31}$, a Ralf Dahrendorf y a Albert Hirschman. Norberto Bobbio ha relacionado los procesos sociales conflictivos con la definición, reivindicación, positivización y especificación de los derechos subjetivos, que "surgen gradualmente de las luchas que el hombre combate por su emancipación y de la transformación de las condiciones de vida que estas luchas producen”32. Por lo demás, en la reflexión teórico-jurídica acerca de la especificidad de

28. El mismo Ferrajoli se aparta de los que él llama universalismo axiológico y universalismo sociológico, denunciando los engaños metaético, jurídico y ético-político a ellos subyacentes (ibid., II, pp. 58-61).

29. B. de Sousa Santos, Derecho y emancipación, p. 217.

30. R. von Jhering, Der Kampf um's Recht, Mainz-Wien, 1891.

31. L. Coser, The Functions of Social Conflict, The Free Press, New York, 1964.

32. N. Bobbio, L'età dei diritti, Einaudi, Torino, 1994, p. 26; cfr. pp. XIII-XIV. 
los derechos subjetivos respecto de otras modalidades jurídicas, la actividad de la reivindicación (claiming) se considera como lo que confiere a los derechos su contenido específico, aquel excedente semántico y simbólico que no forma parte de los deberes correlativos. Para Joel Feinberg, el "empleo característico" de los derechos, "and that for which they are distinctively well suited, is to be claimed, demanded, affirmed, insisted upon": $y$ "what is called 'human dignity' may simply be the recognizable capacity to assert claims" ${ }^{33}$. Esta tesis se puede relacionar con el análisis de los procesos de formación del derecho (juris genesis) elaborado por Robert Cover y Frank Michelman. Este último propone el movimiento por los derechos civiles de los afroamericanos como ejemplo de un proceso triangular en que un grupo desfavorecido emplea los espacios de su "ciudadanía parcial" y hace hincapié sobre ella para movilizarse y exigir que sus derechos sean ampliados. En este proceso, el poder judicial puede ofrecer una contribución importante reconociendo jurisdiccionalmente la legitimidad de algunas peticiones, a las que pueden seguir innovaciones en la legislación y en las políticas públicas ${ }^{34}$.

El hecho de que, en el derecho global, los tribunales jueguen un papel cada vez más decisivo en la protección y en la misma definición de los derechos se puede considerar una adaptación funcional del derecho global, que facilita decisiones flexibles y rápidas con respecto a la temporalidad de los mercados. Sin embargo, otros denuncian el riesgo de una forma de paternalismo de los jueces que concluiría en la neutralización política. En efecto, también en los sistemas jurídicos nacionales el reconocimiento judicial de los derechos ha sido ineficaz sin el apoyo de una movilización de la sociedad y de la opinión pública, ni los tribunales son capaces de definir autónomamente las necesidades a tutelar o los sujetos mismos de los derechos. Y -claro está- los tribunales no desempeñan necesariamente un papel activo en la expansión de los derechos, tal como demuestran muchas experiencias: piénsese en la época Lochner de la Corte Suprema de Estados Unidos y en las sentencias recientes de la Cedu y de la Corte de Justicia de la UE. Sin embargo, otras experiencias -como la ya citada afirmación de los derechos civiles de los afroamericanos, el tema de la jurisprudencia y de la legislación italiana sobre el aborto, la evolución jurisdiccional del patrimonio constitucional europeo, las transformaciones del derecho del trabajo y del derecho sindical en los años sesenta y setenta- destacan una interesante relación entre procesos y conflictos sociales, jurisdicción y acción político-institucional. Incluso en la dimensión global, en donde el espacio

33. J. Feinberg, "The Nature and Valude of Rights", en Rights, Justice, and the Bounds of Liberty, Princeton University Press, Princeton, 1980, p. 151.

34. F. Michelman, "Law’s Republic", en The Yale Law Journal, 97, 1988. Cfr. también S. Benhabib, The Rights of Others. Aliens, Residents, and Citizens, Cambridge University Press, New York, 2004. 
del derecho jurisprudencial no puede ser sino muy amplio, este puede adquirir significados muy diferentes dependiendo de los sujetos y de los procesos sociales a los que se refiere. Los jueces pueden actuar como meros ejecutores de la voluntad de las potencias imperiales o de las corporaciones transnacionales, pero también pueden discutir con los grupos comprometidos en la "lucha por los derechos", contribuyendo al desarrollo del inventario de los derechos y sobre todo de los medios para tutelarlos. Si no se puede restaurar el paradigma constitucionalista conforme a los ordenamientos nacionales -que presupondría una reducción regresiva de la pluralidad competitiva de sujetos sociales, políticos y jurídicos y de la complejidad de principios y sistemas normativos- el derecho transnacional igual podría reconquistar su prescriptividad, desarrollando formas de tutela de los sujetos más débiles. Esto ocurrirá a condición de que los derechos no sean octroyé por los jueces, según una ideología paternalista: es necesario que sigan siendo la expresión jurídica del claiming.

\section{Gobernanza global: ¿neutralización de los conflictos?}

¿Esto es posible hoy día? En el siglo XX el lenguaje de los derechos permitió expresar las reivindicaciones de clases, grupos y movimientos sociales de manera prejurídica, como una especie de semiacabado que facilitó su positivización en principios constitucionales, normas legislativas, medidas administrativas y garantías para convertirlos en reales. Esto era aún más frecuente si había líneas de fractura evidentes en la sociedad -partiendo de aquella entre los grupos por motivos económicos-, si los movimientos sociales tenían formas estables de organización y los partidos políticos funcionaban como interfaz entre estos movimientos y las instituciones (que, a su vez, se abrieron y transformaron favoreciendo la inclusión en la ciudadanía social). Al principio del siglo XXI, el panorama parece ser muy diferente. La evolución postfordista de la producción industrial y la tercerización han favorecido la precarización de las relaciones laborales y la dispersión de los lugares de trabajo. Las grandes agrupaciones de mano de obra, que eran la base de la organización sindical y del desarrollo de la conciencia de clase, han dejado el paso a redes discontinuas y desmalladas que ponen en relación vidas precarias cuyos tiempo de trabajo y tiempo "libre" se cruzan y sobreponen. Por otra parte, incluso cuando los trabajadores están en los mismos espacios físicos prevalece la lógica del outsourcing y de la flexibilidad: diferentes empresas los contratan con contratos y salarios variados y con derechos muy diversos. 
Las oportunidades de reivindicar renta, tutelas y garantías están en peligro a causa de la deslocalización, de la tendencia de los capitales a abandonar la producción por las finanzas, de la globalización de lo que Marx llamaba "ejército industrial de reserva". Además, también funcionan dispositivos de neutralización de los conflictos. Ferrarese considera la gobernanza "inherently pacifying" a través de la implicación de los stake holders y la reducción de los conflictos principales por intereses localizados: "la gobernanza también pone punto final al conflicto político"35.

En el escenario global hay muchos conflictos. Después de 2000, precisamente la resistencia a las políticas neoliberales fue el ámbito común de una nueva fase de luchas, que intentaron relacionarse con la red del "movimiento de los movimientos". A su vez, la crisis global dio lugar a movilizaciones, desde Wall Street hasta las periferias urbanas, desde Plaza Syntagma hasta los campos asiáticos. En algunos casos estos movimientos dieron lugar a formas organizativas originales, influyeron en la agenda y hallaron interlocutores en algunas fuerzas políticas, a veces ya existentes o creando otras. Sin embargo, las relaciones entre movilización de los subalternos, organización sindical y sistema político no son las mismas que las del siglo XX. Los sindicatos tradicionales siguen siendo casi incapaces de organizar a los interinos y parados, ni saben moverse en lo transnacional. La disgregación entre movimientos y política institucional -sobre todo la de los partidos reformistas- sigue siendo bastante amplia y el sistema jurídico parece no aceptar las reivindicaciones, mientras tolera más las razones del establishment que los pedidos procedentes “de abajo”. Muchas víctimas de la crisis -sobre todo los jóvenesparecen no saber movilizarse, mientras hay mucha insatisfacción respecto de chivos expiatorios, etnias minoritarias, religiones “ajenas”, inmigrados. Las fronteras vuelven a ensangrentarse y los mares devuelven los cuerpos.

Hasta aquí hablamos de las formas de conflictos relativas a las necesidades "materiales" y a los intereses económicos. Si pasamos a los conflictos "culturales", que atañen al reconocimiento de identidad, el tema parece ser aún más fragmentado. Se trata de conflictos típicos de las últimas décadas del siglo pasado con características muy diferentes - de la emancipación de los pueblos indígenas a la secesión de nacionalidad y etnias fuertes, a la afirmación de visiones fundamentalistas de los credos religiososy formas muy desiguales - de las "revoluciones de terciopelo" al terrorismo, a los genocidios-. Hoy día parecen estribar en la expresión más violenta de los autoproclamados “califatos". Acontecimientos dramáticos como la masacre de Charlie Hebdo relanzan el

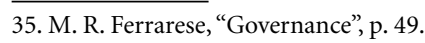


lenguaje de la guerra, mientras los movimientos en contra de la "islamización" de Europa cosechan éxito pero se traducen en medidas administrativas mínimas. Desde cuando apareció en 1993, la tesis acerca del "choque de civilizaciones" ${ }^{36}$ fue considerada por la mayoría científicamente infundada. Sin embargo, "las personas actúan como si el choque entre civilizaciones se diera y, por consiguiente, lo convierten en real" ${ }^{37}$. Incluso los intelectuales progresistas que guardan las distancias de la tesis de Huntington afirman que la base de los más peligrosos conflictos contemporáneos es el fanatismo religioso, sobre todo islámico ${ }^{38}$, hasta eliminar las raíces económicas y geopolíticas de los conflictos identitarios ${ }^{39}$. La búsqueda de una forma de overlapping consensus sobre los derechos humanos ${ }^{40}$ a partir de la problematización de los topoi de su propia tradición cultural ${ }^{41}$ parece inútil.

Tampoco son útiles las tentativas de enmarcar los conflictos contemporáneos en un paradigma unitario. Michael Hardt y Antonio Negri sostienen que en el "Imperio" global triunfa la muchedumbre, pues "all those who work under the rule of capital and thus potentially as the class of those who refuse the role of capital" ${ }^{42}$. El pasaje de la producción meramente económica a la producción inmaterial, o biopolítica, el desarrollo del mercado global, la extensión global de la gubernamentalidad disciplinar están relacionados con el crecimiento capitalístico pero también implican una nueva forma de producción que tiene "intimate relation with cooperation, collaboration, and communinication", y que se basa en lo "common" ${ }^{43}$. De tal forma que la misma lógica funcional de la globalización produzca el sujeto político antagonista, volviendo a relacionar entre sí grupos, clases, núcleos sociales diferentes, de las metrópolis a los campos, del Norte postindustrial a los países emergentes, a las áreas más pobres de Asia y África.

Si el pasaje de lo potencial a lo actual de la multitud necesita de acción política, es la producción biopolítica la que exhibe el modelo; puesto que produce en común y produce lo común, la multitud toma decisiones políticas prescindiendo de una lógica jerárquica, en la base del modelo de una red neuronal o de un programa Open Source. ¿Pero cómo ocurrirá eso? Tal vez con una especie de determinismo histórico que inter-

\footnotetext{
36. S. Huntington, The Clash of Civilizations and the Remaking of World Order, Simon \& Schuster, New York, 1996.

37. C. Bottici, B. Challand, The Mith of the Clash of Civilizations, Routledge, London-New York, 2010, p. 20.

38. M. Walzer, "Islamism and the Left", en Dissent, Winter 2015.

39. S. Benhabib, "Piety or Rage? On the Charlie Hebdo Massacres", en ResetDOC, 1/12/2015http://www.resetdoc.org/ story/00000022481.

40. C. Taylor, "Conditions of an Unforcerd Consensus on Human Rights", in J. R. Bauer, D. A. Bell (eds.), The East Asian Challenge for Human Rights, Cambridge University Press, Cambridge, 1999.

41. A. An-Na'im, Toward an Islamic Reformation, Syracuse University Press, Syracuse-New York, 1996.

42. M. Hardt, A. Negri, Multitude, p. 106.

43. Ibid., p. 147.
} 
preta cualquier movilización como expresión del poder constituyente de la multitud o esperando "un acontecimiento importante", "un suceso realmente insurreccional" 44 en el que se manifiesta un sujeto indeterminado, casi-mesiánico.

Por lo contrario, Ernesto Laclau enfatiza el momento de la voluntad y de la decisión política, por medio de una reinterpretación radical de la teoría gramsciana de la hegemonía. La pretensión hegemónica define las líneas del conflicto político a través de la universalización de una necesidad particular con la que se relacionan, en una "cadena de equivalencias", otras instancias particulares. La lógica del populismo -pues la lógica misma de lo político- presupone una sociedad dividida en "two irreducibile camps", y "Radicality of the chasm involves its conceptual irrepresentability" ${ }^{45}$. Significados políticamente opuestos pueden desenvolver la misma función y, de todas formas, aquellos que son estigmatizados como la imprecisión y la vaguedad de los símbolos, la dimensión afectiva y el papel del inconsciente son fundamentales, así como el papel del líder es esencial, porque permite relacionar entre sí preguntas muy diferentes. Esto vale sobre todo hoy día, en la época del capitalismo globalizado, en donde "the proliferation of heterogeneous points of rupture and antagonisms require incresingly political forms of social reaggregation" 46 . Pero el análisis marxista de las contradicciones de la estructura económica y la tradicional noción de lucha de clase han perdido su significado, mientras "location in the production process loses its centrality in defining the overall identity of social agents" ${ }^{7}$. Por consiguiente, no hay que privilegiar las luchas en las relaciones de producción en "global anti-capitalist struggle"48: es necesario poner en funcionamiento la "razón populista" para crear "vínculos equivalentes entre preguntas sociales muy heterogéneas" ${ }^{49}$.

En ambos modelos, los conflictos sociales se ven como factores de innovación normativa y de producción de un nuevo “orden". Sin embargo, en el modelo Hardt-Negri volvemos a encontrar aquella paradójica fluctuación entre determinismo histórico (o optimístico, wishful thinking) y espera casi-mesiánica presente en otras interpretaciones de los cambios sociales. En la teoría de Laclau todo se encomienda al juego de la hegemonía, entre surgimiento de significantes vacíos, impulsos inconscientes, fracturas no representables y protagonismo de los líderes. En el primer modelo, el poder

\footnotetext{
44. Ibid., p. 358.

45. E. Laclau, On Populist Reason, Verso, London-New York, 2005, pp. 83-84.

46. Ibid., p. 230.

47. J. Butler, E. Laclau, S. Žižek, Contingency, Hegemony, Universality, Contemporary Dialogues on the Left, Verso, London-New York, 2000, p. 300. E. Laclau, On Populist Reason, p. 150.

48. Ibid., p. 150.

49. Ibid., p. 231.
} 
constituyente se considera opuesto al poder constituido, pues brota lo común que produce derecho pero que se opone al rule of law. En el segundo modelo, el enfoque populista de la hegemonía se contrapone al institucional y la especificidad funcional de lo jurídico se pierde en una visión del Estado como "the ethico-political moment of the community" ${ }^{50}$. Pues bien, el derecho parece hallarse solo en el output de los procesos conflictivos. Sin embargo, el derecho también es un recurso del que las partes disponen, y un dispositivo para gestionar los conflictos. Remontémonos a la imagen habermasiana del medium jurídico "transformador": la elevada tensión de los conflictos -piénsese en la lucha mortal del weberiano politeísmo de los valores- se reduce porque se emplean medios jurídicos y no se aspira a la afirmación de valores absolutos o de verdades últimas sino a la definición de normas y principios jurídicos; se posibilitan soluciones de compromiso por medio de las cuales lograr un consenso amplio o, afianzar un modus vivendi. A pesar de no ser un jurista, Nicolás Maquiavelo detectaba en los "tumultos" un factor de innovación jurídica ("leyes y órdenes en beneficio de la libertad pública" ${ }^{51}$ ) y en el gobierno de la ley una condición por medio de la cual los conflictos ocurrían de forma virtuosa ${ }^{52}$; también aludía al derecho como factor fundamental para la creación de sujetos sociales (el pueblo "que mande y que sea bien ordenado", con tanta cordura como para ser capaz de hablar la vox Dei, es el pueblo "encadenado por las leyes" 53 .

En la época moderna, el derecho ha desarrollado un papel importante para la formación y organización de las partes, para la transformación de luchas locales y corporativas en conflictos acerca de cuestiones generales que contraponían ámbitos sociales muy bien definidos. Esto puede ocurrir de formas diferentes. La producción normativa puede contribuir a la institucionalización de los conflictos, preparando un marco jurídico que permite contener la violencia y organizar el resentimiento y la indignación, que a su vez influyen en la innovación social. Piénsese otra vez en el conflicto de clase y en cómo fue reglamentado por las disposiciones legislativas y los principios constitucionales que lo legalizaron, tutelando libertades sindicales y derechos sociales y garantizando formas contractuales colectivas. Por lo contrario, piénsese en los efectos de la desreglamentación en el ámbito del derecho del trabajo, en una fenomenología variada que partiendo de las leyes para la flexibilidad llega a los acuerdos de empresa que excluyen a las organizaciones sindicales, a las disposiciones que ponen en peligro la misma vigencia de

50. Ibid., p. 101.

51. N. Machiavelli, Discorsi, I.4.

52. Además, para Machiavelli, el pueblo se interesa intrínsecamente por el gobierno de la ley: "volendo il popolo vivere secondo le leggi, e i potenti comandare a quelle, non è possibile cappino insieme" [Istorie fiorentine, II. 12]. 53. Ibid., I. 58. 
una legislación erga omnes. En el ámbito del derecho jurisprudencial, piénsese en los efectos de algunas sentencias penales sobre seguridad y contaminación: no solo pueden contribuir a la evolución de la legislación y de las políticas públicas, sino también ser un punto de referencia para la movilización y la organización de las víctimas ${ }^{54}$. Piénsese también en el papel no solo de la jurisdicción, sino también de simples actos administrativos como la transcripción del matrimonio para la afirmación de los derechos LGBT. El reconocimiento de los derechos produce efectos psicológicos y morales significativos y esto influye indirectamente en los itinerarios de construcción de las identidades colectivas y en la definición de los frentes en conflicto. Por lo contrario, sentencias que privilegian la libertad de empresa respecto de los derechos sociales, o que confirman visiones machistas y patriarcales con relación a la violencia sexual, pueden ocasionar en las víctimas la percepción desmoralizante de "no tener derechos" 55 .

Es posible que las transformaciones posmodernas del derecho hayan cortado esta función: de ahí que el derecho no pueda sino seguir, reproducir y eventualmente facilitar la fragmentación social y la proliferación de los lugares del conflicto, garantizando su desarticulación y, como mucho, aceleraría los procesos. Sin embargo, movilizaciones sociales y reivindicaciones siguen volviendo a emerger y aparecen algunas propuestas políticas innovadoras, más allá de la recuperación más o menos moderada de la ortodoxia neoliberal y de las formas más regresivas de populismo. Todo esto parece invitar a la investigación también en el ámbito teórico-jurídico. En el derecho global, realmente los juristas pueden desempeñar un papel importante que, tal vez, no se limite a la invención de instrumentos para la reglamentación de los intercambios jurídicos en la base de las exigencias de los actores del mercado, ni a la restauración more geometrico de un modelo monístico que presagie un Stufenbau global. Un ámbito interesante en el que ejercer la imaginación jurídica podría ser investigar las modalidades de retroactividad de la producción normativa y de la actividad jurisdiccional respecto del contexto social y de los posibles efectos "formativos" de los sujetos sociales y de los actores políticos.

Traducción del italiano de M. Colucciello

\footnotetext{
54. Por ejemplo, es posible que una sentencia que condena por homicidio con dolo eventual al gerente de una multinacional en la que ocurrió un accidente mortal movilice a los trabajadores contra el cierre de una instalación, y quizá induzca el ejecutivo a participar en la discusión activamente.

55. Cfr. A. Honneth, Kampfum Anerkennung, Grammatiksozialer Konflikte, Suhrkamp, Frankfurt a. M., 1992. Por lo que a los efectos psicológicos de los derechos subjetivos se refiere, véase K. Olivecrona, Law as Fact, Oxford University Press, London, 1939.
} 